\title{
Relationship of fatigue with depressive symptoms and level of physical activity in women with breast cancer diagnosis
}

\section{Relação da fadiga com sintomas depressivos e nível de atividade física em mulheres com diagnóstico do câncer de mama}

\author{
Luciana Beatriz Bosi Mendonça de Moura Matoso ${ }^{1}$ \\ (D) https://orcid.org/0000-0002-2610-6466 \\ Leonessa Boing ${ }^{1}$ \\ (D) https://orcid.org/0000-0003-4978-9703 \\ Thainá Korpalski ${ }^{1}$ \\ (D) https://orcid.org/0000-0002-5438-5458 \\ Mirella Dias ${ }^{1}$ \\ (1D) http://orcid.org/0000-0002-2109-3563 \\ Jéssica Moratelli' \\ (D) http://orcid.org/0000-0003-2007-4552 \\ Danielly Yani Fausto ${ }^{1}$ \\ (D) http://orcid.org/0000-0001-5382-7878 \\ Adriana Coutinho de Azevedo Guimarães ${ }^{1}$ \\ (D) https://orcid.org/0000-0001-5167-2921
}

Abstract - Breast cancer is the most frequent in women, resulting in fatigue and depressive symptoms as consequence of treatment, but physical activity can help in this process. The aim of this study was to investigate the relationship between fatigue, depressive symptoms and practice of physical activity of women with breast cancer during treatment or after cancer treatment. This is a cross-sectional study with 179 women $(56.89 \pm 9.4$ years) from the Oncology Research Center - CEPON, using questionnaire on general and clinical information, fatigue (Piper Fatigue Scale) depressive symptoms (Beck Depression Inventory) and physical activity (IPAQ - short version). Women with moderate to severe fatigue underwent physiotherapy ( $p$ $=0.001)$ and women with no fatigue had minimum depressive symptoms ( $\leq 0.001)$. Level of physical activity was not associated with fatigue, with most women being insufficiently active and women with mild fatigue had longer walking time than those without fatigue ( $p$ $=0.049$ ). Women with depressive symptoms were almost three times more likely of having mild to severe fatigue and those who underwent physiotherapy were twice as likely of having mild to severe fatigue. Women with fatigue had greater presence of depressive symptoms. Professionals working in the field of oncology should recommend the practice of physical activity in order to minimize the side effects of treatment and observe depressive symptoms and fatigue in these women.

Key words: Motor activity; Fatigue; Breast neoplasms; Depression.

Resumo - O câncer de mama é o mais frequente nas mulheres, tendo como consequências do tratamento a fadiga e sintomas depressivos, no entanto a atividade física pode auxiliar neste processo. Objetivou-se investigar a relação entre fadiga, sintomas depressivos e prática de atividade física de mulheres com câncer de mama em fase de tratamento ou pós tratamento oncológico. Estudo transversal com 179 mulheres (56,89 9,4 anos) do Centro de Pesquisas Oncológicas - CEPON, utilizando-se um questionário sobre informações gerais e clinicas, fadiga (Escala de Fadiga de Piper), sintomas depressivos (Inventário de Depressão de Beck) e atividade física (IPAQ - versão curta). As mulheres com fadiga moderada a intensa realizavam fisioterapia $(p=0,001)$ e as mulheres com ausência de fadiga apresentaram sintomas depressivos minimos $(p \leq 0,001)$. O nivel de atividade física não se associou com a fadiga, sendo que a maioria das mulheres era insuficientemente ativa e as mulheres com fadiga leve apresentaram um tempo de caminhada maior do que aquelas com ausência de fadiga $(p=0,049)$. Mulheres com presença de sintomas depressivos apresentaram quase três vezes mais chance de apresentar fadiga leve a intensa e aquelas que realizavam fisioterapia apresentaram duas vezes mais chance de apresentar fadiga leve a intensa. Mulheres com fadiga apresentaram maior presença de sintomas depressivos. Os profissionais que atuam na área da saúde oncológica devem recomendar a prática de atividade física a fim de minimizar os efeitos colaterais do tratamento, e prestar atenção aos sinais de sintomas depressivos e fadiga nestas mulheres.

Palavras-chave: Atividade motora; Fadiga; Neoplasias da mama; Depressão.
1 Santa Catarina State University. Florianopolis, SC. Brazil.

Received: September 09, 2018 Accepted: July 03, 2019

How to cite this article Matoso LBBMM, Boing L, Korpalski T, Dias M, Moratelli J, Fausto DY, Guimarães ACA. Relationship of fatigue with depressive symptoms and level of physical activity in women with breast cancer diagnosis. Rev Bras Cineantropom Desempenho Hum 2020, 22:e59189. DOI: http://dx.doi.org/10.1590/19800037.2020v22e59189

Copyright: This work is licensed under a Creative Commons Attribution 4.0 International License. 


\section{INTRODUCTION}

Cancer is now a worldwide public health problem; in 20 years, it is estimated that the number of new cancer cases is expected to increase by $57 \%{ }^{1}$. Breast cancer, on a worldwide scale, is in second place among the most common types of cancer, and in women, it is the most frequent, reaching $25 \%$ of all cancers ${ }^{1}$. In Brazil, for the 2018-2019 years, approximately 600 thousand new cases of cancer are expected to occur; in women, breast cancer is the most frequent (60 thousand), which corresponds to $29.5 \%$ with estimated risk of 56.33 cases per 100 thousand women ${ }^{2}$. In the state of Santa Catarina, for the 2018/2019 years, 2190 new cases of breast cancer are estimated and, in the capital, (Florianopolis), 200 new cases ${ }^{2}$.

Characterized as a multifactorial disease that results from the uncontrolled and abnormal multiplication of breast cells, in which some of the symptoms include presence of nodule, thickening, swelling, distortion, sensitivity, skin irritation, redness, scales and nipple abnormalities or spontaneous nipple secretion ${ }^{3}$. Treatment options are varied, and for this specific type of cancer, surgery, radiotherapy, chemotherapy and hormone therapy are mainly indicated ${ }^{4}$.

When submitted to treatment, women may suffer physical, psychological, emotional or social consequences ${ }^{5}$. Fatigue, defined as an unpleasant physical sensation, with symptoms of extreme tiredness and exhaustion, is considered one of the most prevalent consequences in cancer patients, severely impacting quality of life, decreasing daily functional capacity ${ }^{6}$. Another consequence present in these women is depressive symptoms ${ }^{6,7}$, which after breast cancer diagnosis, are normally related to treatment with chemotherapy and surgery ${ }^{7}$.

Thus, an alternative and non-pharmacological treatment may be the practice of physical activity, which has been related to improvement of the functional declines of women undergoing breast cancer treatment ${ }^{8}$. Evidence shows positive effects of duly prescribed and well-oriented physical activities ${ }^{9}$ and that women with higher levels of physical activity have decreased fatigue, depressive symptoms and better quality of life in genera $1^{10}$. There are several activities that can be performed, including yoga ${ }^{11}$, dance ${ }^{12}$, Tai chi ${ }^{13}$, walking ${ }^{14}$, among others.

However, little is known about the relationship between fatigue and the presence of depressive symptoms, which is linked to the treatment modalities for breast cancer. These side symptoms can also be related to the practice of physical activity in order to improve the quality of life of these women. Given the importance of breast cancer in public health worldwide, the negative effects of treatment and its relationship with physical activity, the aim of this study was to investigate the relationship between fatigue, depressive symptoms and physical activity in women with breast cancer undergoing treatment or after treatment.

\section{METHOD}

This is a cross-sectional study with the participation of 179 women with 
mean age of $56.89 \pm 9.4$ years, who were selected from the database of the master's thesis "Physical activity, quality of life and associated factors in women after breast cancer diagnosis" held at the Center for Oncological Research - CEPON. CEPON is characterized as a public service of reference in the treatment of cancer patients in the state of Santa Catarina, as well as a reference center of WHO - World Health Organization for palliative medicine in Brazil.

Inclusion criteria were a) women diagnosed with stage I to III breast cancer; b) age group of 40-80 years and c) undergoing treatment or following post-treatment at CEPON / SC. Exclusion criterion was defined as being illiterate.

For data collection, self-administered questionnaire in the form of individual interview composed of validated instruments was used, being divided into four parts: (a) General and clinical information; (b) Fatigue; (c) Physical activity; (d) Depressive symptoms.

a) General and clinical information (all self-reported): characterization of women regarding age, marital status, schooling, number of children, menopause, presence of other diseases, surgical and treatment method, presence of lymphedema, participation in physiotherapy, weight and height (self-reported) to calculate Body Mass Index - BMI (weight / height ${ }^{2}$ ). For BMI classification (weight status), the World Health Organization ${ }^{15}$ protocol was used, which is divided into: thinness (BMI <18.5); eutrophic (BMI 18.5-24.9); overweight (BMI 25.0-29.9); pre-obesity and obesity (BMI> 30.0). For statistical analysis and due to the small sample size, weight status was as follows: normal weight, considering thin and eutrophic groups; and overweight, including pre-obesity and obesity groups. Socioeconomic classification was made according to $\mathrm{IBGE}^{16}$. The population is classified into economic levels through the average monthly family income. The 2014 minimum wage of $\mathrm{R} \$ 724.00$ was adopted. Socioeconomic classes are: (1) Class A, those that receive monthly family income above 20 minimum wages; (2) Class B, those receiving 10 to 20 minimum wages; (3) Class C, including those receiving 4 to 10 minimum wages; (4) Class $\mathrm{D}$, those who receive 2 to 4 minimum wages; and (5) class E, receiving up to 2 minimum wages. For statistical purposes, and due to the small sample size in each category, profile was categorized as high economic level (A and $\mathrm{B})$, medium economic level (C), and low economic level (D and E);

b) Fatigue: Piper Fatigue Scale (PFS), which considers the patient's fatigue perception in a subjective and self-reported way ${ }^{17}$ with 22 items divided into 3 domains: behavioral (items 2 to 7 ), which includes functional capacity with personal issues, social activities and sexual relationships; affective (items 8 to 12), which seeks to find the meaning given to fatigue; sensory / psychological (items 13 to 23), which recognize self-perception, emotional and cognitive components in the presence of fatigue. Each item is scored on a scale ranging from 0 to 10 . Scores of 
domains and total score also vary between 0 and 10 and were obtained by summing the score of each item and dividing it by the number of items in each domain, or 22, when calculating the total score. Scores were categorized as follows: 0 as absence; between 0.1 and 4.9 as mild fatigue; between 5 and 10 as moderate or intense fatigue.

c) Depressive symptoms: Beck's Depression Inventory (BDI), a selfadministered questionnaire originally developed by Beck et al. ${ }^{18}$. It has 21 multiple-choice objective questions related to depressive symptoms with four answer options that vary in scores from zero to three (0-3) The sum of scores of each item provides a total score, which ranges from 0 to 63 The closer to 0 , the greater the absence of depressive symptoms, and the closer to 63, the higher the degree of depressive symptoms. The symptoms considered by BDI are: sadness, pessimism, feeling of failure, dissatisfaction, feeling of guilt, expectation of punishment, low self-esteem, self-criticism, suicidal ideas, crying crisis, irritability, social withdrawal, indecision, body image distortion, inhibition to work, sleep disorders, fatigue, loss of appetite, weight loss, somatic concern and decreased libido ${ }^{19}$. The interpretation of scores occurred according to the standardization of the Cognitive Therapy Center used in studies with cancer patients: scores from 0 to 10 , absence of symptoms; scores from 11 to 18, mild depressive symptoms; scores from 19 to 29, moderate depressive symptoms; scores from 30 to 63, severe depressive symptoms ${ }^{20}$.

d) Physical activity: International physical activity questionnaire (IPAQ - short version) ${ }^{21}$. IPAQ is a self-administered instrument, which seeks to verify the number of times the individual practices at least 10 continuous minutes of walking, moderate and vigorous physical activity per week. For the final calculation of physical activity, the duration and frequency of the different types of activities were summed (walking + moderate + vigorous). The classification used was that of the instrument itself $\mathrm{f}^{21}$, which meets recommendations for cancer patients from the American College of Sports Medicine ${ }^{22}$. Thus, women in the present study were classified as: Insufficiently Active - those who do not practice physical activities or practice for up to 10 continuous minutes a week, but insufficiently to be classified as active, that is, less than 150 minutes of moderate activity or 75 minutes of vigorous activity per week. Sufficiently Active - Patients comply with the following recommendations: a) vigorous physical activity $\geq 3$ days / week and $\geq$ 25 minutes / session; b) moderate $\geq 5$ days / week and $\geq 30$ minutes / session; c) any combined activity: $\geq 5$ days / week and $\geq 150 \mathrm{~min} /$ week.

Data collection took place at the chemotherapy, radiotherapy, physiotherapy center of CEPON and in the waiting rooms of doctors' offices and mammography and ultrasound examinations, carried out by researchers from the Laboratory of Research in Leisure and Physical Activity - LAPLAF, with the guidance of the main researcher, on a previously 
scheduled day and time, with approximate duration of 20 minutes. The project was approved by the Ethics Research Committee on Human Beings (CEPSH) of UDESC, protocol No. 688.548 and by the Ethics Research Committee of CEPON (CEP), protocol No. 818.174. Participants signed the Free and Informed Consent Form and were invited to participate in the study voluntarily.

Statistical analysis was performed using the SPSS software version 20.0 using inferential statistics. The Chi-Square test was used to associate general and clinical variables with fatigue, classifying women with no fatigue, mild fatigue, and moderate to severe fatigue. To verify data normality, the Kolmogorv Smirnov test was used. Since data normality was not found, the Kruskal Wallis non-parametric test and Dunn's post hoc test was used to compare fatigue levels with physical activity and depressive symptoms $(\mathrm{p}<0.05)$. For the relationship between fatigue, depressive symptoms and physical activity, crude and adjusted binary logistic regression was also used, in which the dependent variable was fatigue, and for its analysis in a dichotomous way, groups were classified into absence of fatigue and mild to intense fatigue, being the presence of mild to intense fatigue as reference category. Independent variables (exposure factors) used in the regression analysis were: depressive symptoms (absence or presence of depressive symptoms), level of physical activity (insufficiently active or sufficiently active), physiotherapy (yes or no), type of surgery (no surgery, mastectomy or conservative surgery), concluded treatment (yes or no) and presence of lymphedema (yes or no). For adjusted analysis, only variables that presented $\mathrm{p}<0.20$ in the crude analysis were included.

\section{RESULTS}

Table 1 shows the general and clinical characteristics of women with breast cancer who participated in this study. Most patients had partner, had up to elementary school, low socioeconomic class (D + E), overweight and had one or more children. Regarding clinical characteristics, most had no other diseases in addition to cancer and underwent mastectomy without breast reconstruction, were under treatment with chemotherapy, at menopause, without self-report of lymphedema and not undergoing physiotherapy. When depressive symptoms and physical activity were observed, most women had minimal or mild depressive symptoms, and were insufficiently active.

Table 2 shows the general and clinical characteristics of women according to fatigue. It is important to note that most women who had mild fatigue had partner and were overweight; women who reported absence of fatigue had three or more children. There was significant relationship with women who underwent physiotherapy $(p=0.001)$, and with those who participated in sessions had moderate to intense fatigue and those who did not participate presented absence of fatigue. In the other variables, no significant associations were found. 
Table 1. General and clinical characteristics of women with breast cancer CEPON - 2014/2015. Florianopolis $(n=179)$.

\begin{tabular}{|c|c|}
\hline & $\begin{array}{c}\text { Total } \\
\%(95 \% \mathrm{CI})\end{array}$ \\
\hline \multicolumn{2}{|l|}{ Marital status } \\
\hline Without partner & $41.9(34-49)$ \\
\hline With partner & $58.1(50-65)$ \\
\hline \multicolumn{2}{|l|}{ Schooling } \\
\hline Elementary education & $53.1(45-60)$ \\
\hline High School & $34.1(28-41)$ \\
\hline Higher Education & $12.8(8-18)$ \\
\hline \multicolumn{2}{|l|}{ Socioeconomic class } \\
\hline Upper class $(\mathrm{A}+\mathrm{B})$ & $3.9(1-7)$ \\
\hline Middle class (C) & $14.0(9-19)$ \\
\hline Low class $(D+E)$ & $82.1(75-87)$ \\
\hline \multicolumn{2}{|l|}{ Weight status } \\
\hline Normal weight & $28.0(21-35)$ \\
\hline Overweight & $72.0(64-78)$ \\
\hline \multicolumn{2}{|l|}{ Number of children } \\
\hline None & $9.5(6-15)$ \\
\hline One or two & $45.8(38-53)$ \\
\hline Three or more & $44.7(37-52)$ \\
\hline \multicolumn{2}{|c|}{ Presence of diseases other than cancer } \\
\hline Yes & $49.7(42-56)$ \\
\hline No & $50.3(43-57)$ \\
\hline \multicolumn{2}{|l|}{ Type of surgery } \\
\hline Mastectomy & $57.5(50-64)$ \\
\hline Conservative surgery & $36.9(30-44)$ \\
\hline No surgery & $5.6(3-9)$ \\
\hline \multicolumn{2}{|l|}{ Reconstruction } \\
\hline Immediate breast reconstruction & $16(11-22)$ \\
\hline Late breast reconstruction & $8.3(5-13)$ \\
\hline No reconstruction & $75.7(68-81)$ \\
\hline \multicolumn{2}{|l|}{ Menopause } \\
\hline Yes & $87.9(82-91)$ \\
\hline No & $12.1(8-17)$ \\
\hline \multicolumn{2}{|l|}{ Type of treatment } \\
\hline Chemotherapy & $41.5(33-50)$ \\
\hline Radiotherapy & $26.2(19-34)$ \\
\hline Hormone therapy & $32.3(24-40)$ \\
\hline \multicolumn{2}{|l|}{ Lymphedema } \\
\hline Yes & $45.0(37-52)$ \\
\hline No & $55.0(47-62)$ \\
\hline \multicolumn{2}{|l|}{ Physiotherapy } \\
\hline Yes & $42.5(35-49)$ \\
\hline No & $57.5(50-64)$ \\
\hline \multicolumn{2}{|l|}{ Depressive symptoms } \\
\hline Minimum & $53.9(46-61)$ \\
\hline Mild & $27.0(20-33)$ \\
\hline Moderate & $15.7(11-21)$ \\
\hline Severe & $3.4(1-7)$ \\
\hline \multicolumn{2}{|l|}{ Level of physical activity } \\
\hline Insufficiently active & $69.3(62-75)$ \\
\hline Sufficiently active & $30.7(24-38)$ \\
\hline
\end{tabular}


Table 2. General and clinical characteristics of women with breast cancer according to fatigue, CEPON - 2014/2015. Florianopolis $(n=179)$.

\begin{tabular}{|c|c|c|c|c|}
\hline & $\begin{array}{c}\text { Absence } \\
\text { of fatigue } \\
(n=46)\end{array}$ & $\begin{array}{l}\text { Mild fatigue } \\
\qquad(\mathrm{n}=88)\end{array}$ & $\begin{array}{l}\text { Moderate to } \\
\text { severe fatigue } \\
(n=45)\end{array}$ & $p$ value \\
\hline \multicolumn{4}{|l|}{ Marital status } & 0.334 \\
\hline Without partner & 47.8 & 36.4 & 46.7 & \\
\hline With partner & 52.2 & 63.6 & 53.3 & \\
\hline \multicolumn{4}{|l|}{ Schooling } & 0.863 \\
\hline Elementary education & 47.8 & 53.4 & 57.8 & \\
\hline High School & 37.0 & 35.2 & 28.9 & \\
\hline Higher Education & 15.2 & 11.4 & 13.3 & \\
\hline \multicolumn{4}{|l|}{ Socioeconomic class } & 0.255 \\
\hline Upper class $(A+B)$ & 2.2 & 2.3 & 8.9 & \\
\hline Middle class $(\mathrm{C})$ & 13.0 & 17.0 & 8.9 & \\
\hline Low class $(D+E)$ & 84.8 & 80.7 & 82.2 & \\
\hline \multicolumn{4}{|l|}{ Weight status } & 0.608 \\
\hline Normal weight & 32.6 & 24.7 & 29.5 & \\
\hline Overweight & 67.4 & 75.3 & 70.5 & \\
\hline \multicolumn{4}{|l|}{ Number of children } & 0.715 \\
\hline None & 10.9 & 9.1 & 8.9 & \\
\hline One or two & 37.0 & 50.0 & 46.7 & \\
\hline Three or more & 52.2 & 40.9 & 44.4 & \\
\hline \multicolumn{4}{|c|}{ Presence of diseases other than cancer } & 0.148 \\
\hline Yes & 60.9 & 43.2 & 51.1 & \\
\hline No & 39.1 & 56.8 & 48.9 & \\
\hline \multicolumn{4}{|l|}{ Type of surgery } & 0.358 \\
\hline Mastectomy & 54.3 & 53.4 & 68.9 & \\
\hline Conservative surgery & 41.3 & 38.6 & 28.9 & \\
\hline No surgery & 4.3 & 8.0 & 2.2 & \\
\hline \multicolumn{4}{|l|}{ Reconstruction } & 0.845 \\
\hline Immediate breast reconstruction & 15.9 & 16 & 15.9 & \\
\hline Late breast reconstruction & 4.5 & 8.6 & 11.4 & \\
\hline No reconstruction & 79.5 & 75.3 & 72.7 & \\
\hline \multicolumn{4}{|l|}{ Menopause } & 0.688 \\
\hline Yes & 84.8 & 88.2 & 90.7 & \\
\hline No & 15.2 & 11.8 & 9.3 & \\
\hline \multicolumn{4}{|l|}{ Type of treatment } & 0.063 \\
\hline Chemotherapy & 26.7 & 49.2 & 40 & \\
\hline Radiotherapy & 43.3 & 23.1 & 17.1 & \\
\hline Hormone therapy & 30.0 & 27.7 & 42.9 & \\
\hline \multicolumn{4}{|l|}{ Lymphedema } & 0.204 \\
\hline Yes & 34.1 & 46.9 & 52.3 & \\
\hline No & 65.9 & 53.1 & 47.7 & \\
\hline \multicolumn{4}{|l|}{ Physiotherapy } & 0.001 \\
\hline Yes & 26.1 & 39.8 & 64.4 & \\
\hline No & 73.9 & 60.2 & 35.6 & \\
\hline
\end{tabular}

Data in Table 3 show the presence of depressive symptoms and level of physical activity according to fatigue perception. Significant association 
can be observed between depressive symptoms and fatigue ( $\mathrm{p} \leq 0.001)$, in which most women who reported absence of fatigue had minimal depressive symptoms (76.1\%), and most women who presented moderate to severe fatigue showed moderate depressive symptoms (40.0\%). The level of physical activity did not show significant relationship with fatigue, but it can be highlighted that most women with moderate to intense fatigue (75.6\%) were also insufficiently active.

Table 3. Presence of depressive symptoms and physical activity in women with breast cancer according to fatigue. CEPON - 2014/2015. Florianopolis $(n=179)$.

\begin{tabular}{lcccc}
\hline & $\begin{array}{c}\text { Absence of } \\
\text { fatigue } \\
(\mathrm{n}=46)\end{array}$ & $\begin{array}{c}\text { Mild fatigue } \\
(\mathrm{n}=88)\end{array}$ & $\begin{array}{c}\text { Moderate to } \\
\text { severe fatigue } \\
(\mathrm{n}=45)\end{array}$ & p value \\
\hline $\begin{array}{l}\text { Depressive symptoms } \\
\quad \text { Minimum }\end{array}$ & 76.1 & 59.8 & 20.0 & $\leq 0.001$ \\
\hline Mild & 19.6 & 31.0 & 26.7 & \\
Moderate & 4.3 & 9.2 & 40.0 & \\
$\quad$ Severe & 0 & 0 & 13.3 & 0.521 \\
Level of physical activity & & & & \\
\hline Insufficiently active & 69.6 & 65.9 & 75.6 & \\
$\quad$ Sufficiently active & 30.4 & 34.1 & 24.4 & \\
\hline
\end{tabular}

A comparison of physical activity intensities was performed according to fatigue (table 4). Women with mild fatigue had significantly longer walking time than those with no fatigue and the other variables did not show significant differences. However, it is important to highlight that all practice time averages were lower in women who reported moderate to intense fatigue.

Table 4. Comparison of physical activity intensities of women with breast cancer according to fatigue, CEPON - 2014/2015. Florianopolis $(n=179)$.

\begin{tabular}{lllllll}
\hline Variables (min/day) & Total & $\begin{array}{l}\text { Absence of fatigue A } \\
(\mathrm{n}=46)\end{array}$ & $\begin{array}{l}\text { Mild fatigue B } \\
(\mathrm{n}=88)\end{array}$ & $\begin{array}{l}\text { Moderate to severe } \\
\text { fatigue C } \\
(\mathrm{n}=45)\end{array}$ & $\mathrm{p}$ value & Post Hoc \\
\hline Walking time & $20.4 \pm 27.0$ & $16.1 \pm 25.3$ & $24.6 \pm 28.4$ & $16.5 \pm 25.3$ & 0.049 & $\mathrm{~A}<\mathrm{B}=\mathrm{C}$ \\
Moderate PA time & $12.5 \pm 30.5$ & $13.8 \pm 33.7$ & $14.6 \pm 33.7$ & $7.1 \pm 17.7$ & 0.576 & $\mathrm{~A}=\mathrm{B}=\mathrm{C}$ \\
Vigorous PA time & $3.1 \pm 16.9$ & $0.0 \pm 0.0$ & $5.1 \pm 22.2$ & $2.6 \pm 12.5$ & 0.194 & $\mathrm{~A}=\mathrm{B}=\mathrm{C}$ \\
$\begin{array}{l}\text { Moderate + vigorous } \\
\text { PA time }\end{array}$ & $15.7 \pm 40.8$ & $13.8 \pm 33.7$ & $19.7 \pm 50.0$ & $9.7 \pm 23.3$ & 0.653 & $\mathrm{~A}=\mathrm{B}=\mathrm{C}$ \\
Total PA time & $36.1 \pm 57.0$ & $30.0 \pm 42.4$ & $44.4 \pm 69.0$ & $26.3 \pm 40.4$ & 0.193 & $\mathrm{~A}=\mathrm{B}=\mathrm{C}$ \\
\hline
\end{tabular}

Note. Values presented in mean and standard deviation. Min / day - minutes per day. PA - Physical activity. Kruskal Wallis test with Dunn's Post Hoc.

In table 5, a binary logistic regression analysis was performed for the odds ratio of presence of mild to severe fatigue and it was observed that women who reported presence of depressive symptoms were almost three times more likely of having mild to severe fatigue when compared to those with no depressive symptoms, both in the crude analysis $(\mathrm{p}=0.001)$ and in the adjusted analysis $(\mathrm{p}=0.005)$. Likewise, patients who were undergoing physiotherapy were twice more likely of having mild to severe fatigue when compared to those who were not undergoing physiotherapy, both 
in the crude analysis $(\mathrm{p}=0.011)$ and in the adjusted analysis $(\mathrm{p}=0.037)$.

Lymphedema was not significant in the adjusted analysis; however, the crude analysis showed that women with lymphedema were almost two times more likely of having mild to severe fatigue when compared to women without presence of lymphedema.

Table 5. Binary Logistic Regression Analysis for the odds ratio of presence of mild to severe fatigue in women after breast cancer diagnosis, CEPON - Florianopolis 2014/2015. $(n=179)$.

\begin{tabular}{|c|c|c|c|c|c|}
\hline Variables & $\%$ & $\begin{array}{l}\text { Crude OR } \\
(95 \% \mathrm{Cl})\end{array}$ & $p$ value & $\begin{array}{c}\text { Adjusted OR } \\
(95 \% \mathrm{Cl})\end{array}$ & $p$ value \\
\hline Depressive symptoms & & & 0.001 & & 0.005 \\
\hline Presence & 49.4 & $3.340(1.612-6.920)$ & & $2.946(1.379-6.296)$ & \\
\hline Absence & 50.6 & 1.00 & & 1.00 & \\
\hline Level of physical activity & & & 0.960 & & \\
\hline Insufficiently active & 69.3 & $0.982(0.474-2.033)$ & & - & \\
\hline Sufficiently active & 30.7 & 1.00 & & - & \\
\hline Physiotherapy & & & 0.011 & & 0.037 \\
\hline Yes & 42.5 & $2.628(1.253-5.513)$ & & $2.476(1.055-5.811)$ & \\
\hline No & 57.5 & 1.00 & & 1.00 & \\
\hline Type of surgery & & & 0.673 & & \\
\hline Mastectomy & 57.5 & $0.710(0.145-3.473)$ & & - & \\
\hline Conservative surgery & 42.5 & 1.00 & & - & \\
\hline Concluded treatment & & & 0.552 & & \\
\hline Yes & 77.1 & $1.266(0.582-2.751)$ & & - & \\
\hline No & 22.9 & 1.00 & & - & \\
\hline Lymphedema & & & 0.094 & & 0.944 \\
\hline Yes & 45.0 & $1.843(0.901-3.768)$ & & $1.031(0.447-2.376)$ & \\
\hline No & 55.0 & 1.00 & & 1.00 & \\
\hline
\end{tabular}

Note. OR: odds ratio; 95\% Cl: confidence interval.

\section{DISCUSSION}

This study aimed to investigate the relationship between fatigue, depressive symptoms and physical activity in women with breast cancer undergoing treatment or after treatment. The results indicated significant association between depressive symptoms and fatigue, but there was no relationship between level of physical activity and fatigue; however, the majority of women was insufficiently active (69.6\%), and when the practice intensity was compared, women with mild fatigue showed longer walking time. Furthermore, by the binary logistic regression, it was observed that patients with presence of depressive symptoms were more likely of having mild to severe fatigue, and those who underwent physiotherapy were more likely of having mild to severe fatigue.

Fatigue was present in most women in this study, corroborating Panobianco et al. ${ }^{6}$, who found high prevalence of fatigue in women with breast cancer. Even though treatment protocols are currently less aggressive, it was found in literature that declines after breast cancer diagnosis can be associated with chemotherapy and surgery treatments ${ }^{7}$. It is important to highlight that most patients in the present study were undergoing chemo- 
therapy treatment, and had undergone mastectomy for breast cancer, which can worsen the fatigue perception in more severe degrees 5 .

This study showed that women undergoing physiotherapy reported significantly higher levels of fatigue when compared to those who were not and were more likely of having mild to severe fatigue. This relationship is possibly since women who have more severe illnesses are those who most seek and need physiotherapy. In addition, another explanation is the fact that there is great physical and psychological exhaustion related to this practice, since it involves effort, discipline, expectation, commuting to the session location and often unpleasant pain sensations.

In this study, fatigue was also significantly associated with presence of depressive symptoms, which in turn are consequences of breast cancer treatments ${ }^{6}$. As expected, the results indicated that most women who reported absence of fatigue and mild fatigue presented minimal depressive symptoms and none of them had severe depressive symptoms. Most women with moderate to severe fatigue had moderate depressive symptoms. By binary logistic regression, it was found that women who had depressive symptoms were almost three times more likely of having mild to severe fatigue. These results corroborate Panobianco et al. ${ }^{6}$ and Ebede et al. ${ }^{23}$, who reported that depression and fatigue can occur concomitantly and directly affect women's quality of life. It is also possible to associate the domains of instruments that assess fatigue and depressive symptoms, which sometimes assess very similar sensations. Fatigue, for example, is included in the assessment of depressive symptoms.

In this study, no significant relationship between fatigue and level of physical activity was found. This finding in consistent with Reis et al. ${ }^{24}$, who with combined training interventions demonstrated that despite reduction in pain, improvement in flexibility and strength, there was no improvement in fatigue in women with breast cancer. Jong et al. ${ }^{25}$ investigated the effect of yoga on the fatigue of patients undergoing chemotherapy and found no significant results. However, there is evidence in literature showing the effectiveness of physical activity and physical exercise for women undergoing treatment and after treatment for breast cancer ${ }^{10}$, for example resistance exercise, which proved to be a possibility to reduce fatigue and maintain quality of life during chemotherapy treatment ${ }^{26}$. In a recent meta-analysis, findings indicate that physical exercise can reduce the presence of fatigue and improve the physical function of women with breast cancer ${ }^{27}$.

However, although there is recommendation by the American College of Sports Medicine ${ }^{22}$ of at least 150 minutes of moderate to vigorous physical activity to patients diagnosed with breast cancer, in this study, most women demonstrated to be insufficiently active (69.6\%). According to results observed in a systematic review that identified that most women in the post-treatment do not reach recommendations for the practice of physical activity ${ }^{11}$.

The shorter physical activity time of these women can be explained by the reduced physical conditions, presence of fatigue as a limiting factor, functional declines and lack of motivation that the disease and the side 
effects of treatment bring ${ }^{5}$, making it impossible for these women to reach recommendations. When comparing the intensities of activities in relation to fatigue, the results showed significant difference in the walking time, in which women with mild fatigue reported longer walking time compared to those with no fatigue. Walking is a pleasant activity, can be practiced in groups and has easy access, low impact and low $\operatorname{cost}^{16}$. In the present study, there were no significant differences in variables time of moderate, vigorous and moderate + vigorous physical activity; however, most women with mild fatigue were those who reported the longest total physical activity time. Women who practiced more time walking and more time practicing total physical activity may be linked and involved in groups of women who share the same experiences and thus collaborate for greater willingness and motivation.

Another finding in this study refers to lymphedema. By binary logistic regression, in the crude analysis, the presence of lymphedema was related to fatigue, showing that women with presence of lymphedema are more likely of having fatigue. Lymphedema is a consequence of breast cancer surgery, being characterized as a chronic condition and affects most women and, corroborating present results, worsens the physical and mental condition ${ }^{28}$. Most women in this study underwent radical surgery and Assis et al. ${ }^{29}$ reported that lymphedema, pain and difficulties in relation to the arm can be caused by this type of surgery, accompanied by radical axillary emptying, which refers again to a relationship with fatigue. In addition, the presence of fatigue along with lymphedema can impair women's functional life, worsen their quality of life and be a reason for not returning to work within five years after treatment ${ }^{30}$.

Some limiting factors are related to the use of the questionnaire as an indirect measure for data collection, not having access to the medical records of these patients, which would facilitate the data collection process regarding possible discomfort and the fact that some data of clinical characteristics were self-reported, as is the case of lymphedema. In addition, the use of the IPAQ instrument - short version that evaluates physical activity practice is a questionnaire of subjective measure and of retrospective nature. Finally, the study has cross-sectional design, making it impossible establishing a long-term cause and effect relationship.

This study positively contributes to literature as it makes an alert to the low levels of physical activity of women and, equally, to the relationship between fatigue and depressive symptoms, two conditions very prevalent in women diagnosed with breast cancer, who are faced with painful feelings never experienced and who demand greater attention in policies to encourage healthy practices.

\section{CONCLUSION}

Significant results were found regarding the association between fatigue and physiotherapy, depressive symptoms and lymphedema. However, no 
association was found between fatigue and physical activity, except for variable walking. Most women reported some degree of fatigue and did not meet recommendations for physical activity for breast cancer patients.

Therefore, health professionals should pay more attention and concern to women with depressive symptoms, who are undergoing physiotherapy and with lymphedema. Physical activity programs that can assist in this treatment period and reduce the presence of fatigue in these women should be implemented.

\section{COMPLIANCE WITH ETHICAL STANDARDS}

\section{Funding}

This study was financed in part by the Coordenação de Aperfeiçoamento de Pessoal de Nível Superior - Brasil (CAPES) - Finance Code 001.

\section{Ethical approval}

Ethical approval was obtained from the local Human Research Ethics Committee - no. 688.548 and the protocol (no. 818.174) was written in accordance with standards set by the Declaration of Helsinki.

\section{Conflict of interest statement}

The authors have no conflict of interests to declare.

\section{Author Contributions}

Conceived and designed the experiments: LBBMMM, LB, ACAG. Performed the experiments: LBBMMM, LB. Analyzed data: LB, TK, JM. Contributed with reagents/materials/analysis tools: JM, TK, DYF, MD. Wrote the paper: LBBMMM, LB, TK, JM, DYF, MD, ACAG.

\section{REFERENCES}

1. World Health Organization. GLOBOCAN 2012: estimated cancer incidence, mortality and prevalence worldwide in 2012. Lion: IARC, 2013. Available from: http://globocan.iarc.fr/Pages/fact_sheets_cancer.aspx [2018 abr 19].

2. Ministério da Saúde. Instituto Nacional De Câncer José Alencar Gomes Da Silva. Coordenação de Prevenção e Vigilância. Estimativa 2018: Incidência de câncer no Brasil. Rio de Janeiro: INCA. 122p, 2018; Available from: http://www.inca. gov.br/estimativa/2018/index.asp [2018 abr 19].

3. American Cancer Society. Cancer Facts \& Figures. Atlanta: American Cancer Society;2017.

4. National Cancer Institute. Type of Cancer Treatment. National Cancer Institute: United States. 2017; Available from: https://www.cancer.gov/about-cancer/treatment/types/ [2017 maio 06].

5. de Ligt KM, Heins M, Verloop J, Smorenburg CH, Korevaar JC, Siesling S. Patient-reported health problems and healthcare use after treatment for early-stage breast cancer. Breast 2019;46:4-11.

6. Panobianco MS, Magalhães PAP, Soares CR, Sampaio BAL, Almeida AM, Gozzo TO. Prevalência de depressão e fadiga em um grupo de mulheres com câncer de mama. Rev Eletr Enferm 2012; 14(3):532-540.

7. Souza BF, Moraes JA, Inocenti A, Santos MA, Silva AEB, Miasso AI. Mulheres com câncer de mama em uso de quimioterápicos: sintomas depressivos e adesão ao tratamento. Rev Latino Am Enferm 2014; 22(5):866-873. 
8. Lipsett A, Barrett S, Haruna F, Mustian K, O'Donovan A. The impact of exercise during adjuvant radiotherapy for breast cancer on fatigue and quality of life: A systematic review and meta-analysis. Breast 2017; 32:144-55.

9. Patsou ED, Alexias GD, Anagnostopoulos FG, Karamouziset MV. Effects of physical activity on depressive symptoms during breast cancer survivorship: a meta-analysis of randomised control trials. ESMO Open 2017; 2(5):1-15.

10. Boing L, Guimarães ACA, Reis NM, RM. Atividade física após o diagnóstico do câncer de mama: revisão sistemática. Motri 2016; 12(2):155-166.

11. Sudarshan M, Petrucci A, Dumitra S, Duplisea J, Wexler S, Meterissian S. Yoga therapy for breast cancer patients: A prospective cohort study. Complement Ther Clin Pract 2013;19(4):227-9..

12. Sturm I, Baak J, Storek B, Traore A, Thuss-Patience P. Effect of dance on cancerrelated fatigue and quality of life. Support Care Cancer 2014; 22 (8):2241-2249.

13. Irwin MR, Olmstead R, Carrillo C, Sadeghi N, Nicassio P, Ganz PA, et al. Tai Chi Chih compared with cognitive behavioral therapy for the treatment of insomnia in survivors of breast cancer: a randomized, partially blinded, noninferiority trial. J Clin Oncol 2017; 35(23):2656-2665.

14. Rowe DA, Welk GJ, Heil DP, Mahar MT, Kemble CD, Calabró MA, et al. Stride Rate Recommendations for Moderate-Intensity Walking. Med Sci Sports Exerc 2011; 43(2):312-318.

15. World Health Organization (WHO). The International Classification of adult underweight, overweight and obesity according to BMI. United States. 2004; Available from: http://apps.who.int/bmi/index.jsp?introPage=intro_3.html [2017 maio 06].

16. Instituto Brasileiro de Geografia e Estatística. Projeção da população do Brasil/ censo. Brasil. 2010; Available from: www.ibge.gov.br [2017 mai 13].

17. Piper BF, Dibble SL, Dodd MJ, Weiss MC, Slaughter RE, Paul SM. The revised Piper Fatigue Scale: psychometric evaluation in women with breast cancer. Oncol Nurs Forum 1998; 25(4):677-84

18. Beck AT, Ward CH, Mendelson M, Mock J, Erbaugh J. An inventory for measuring depression. Arch Gen Psychiatry 1961; 4:561-571.

19. Gandini RC, Martins MCF, Ribeiro MP, Santos DTG. Inventário de Depressão de Beck - BDI: validação fatorial para mulheres com câncer. Psico-USF 2007; 2(1):23-31.

20. Gorestein C, Andrade LHSG. Inventário de depressão de Beck: propriedades psicométricas da versão em português. Rev Psiquiatr Clín 1998; 25(5):245-250.

21. Pardini R, Matsudo S, Matsudo V, Araújo T, Andrade E, Braggion G, et al. Validation of International Physical Questionnaire (IPAQ): pilot study in Brazilian young adults. Med Sci Sports Exerc 1997; 29(6):S5-S9.

22. American College of Sports Medicine. ACSM's Resource Manual for Guidelines for Exercise Testing and Prescription. Philadelphia: Lippincott Williams \& Wilkins; 2010.

23. Ebede CC, Jang Y, Escalante CP. Cancer-Related Fatigue in Cancer Survivorship. Med Clin North Am 2017;101(6):1085-1097.

24. Reis AD, Pereira PTVT, Diniz RR, Castro Filha JGL, Santos AM, Ramallo BT, et al. Effect of exercise on pain and functional capacity in breast cancer patients. Health Qual Life Outcomes 2018;16(1):58.

25. Jong MC, Boers I, Schouten van der Velden AP, Meij S van der, Göker E, TimmerBonte ANJH, et al. A Randomized Study of Yoga for Fatigue and Quality of Life in Women with Breast Cancer Undergoing (Neo) Adjuvant Chemotherapy. J Altern Complement Med 2018;24(9-10):942-953.

26. Schmitz KH, Courneya KS, Matthews C, Demark-Wahnefried W, Galvão DA, Pinto BM, et al. American College of Sports Medicine roundtable on exercise guidelines for cancer survivors. Med Sci Sports Exerc 2010; 42(7):1409-26.

27. Juvet LK, Thune I, Elvsaas IKØ, Fors EA, Lundgren S, Bertheussen G, et al. The effect of exercise on fatigue and physical functioning in breast cancer patients during and after treatment and at 6 months follow-up: A meta-analysis. Breast 2017;33:166-177. 
28. Dominick S, Natarajan L, Pierce JP, Madanat H, Madlensky L. The Psychosocial Impact of Lymphedema-related Distress among Breast Cancer Survivors in the WHEL Study. Psychooncology 2014; 23(9):1049-1056.

29. Assis MR, Marx AG, Magna LA, Ferrigno ISV. Late morbidity in upper limb function and quality of life in women after breast cancer surgery. Braz J Phys Ther 2013; 17(3): 236-243.

30. Schmidt ME, Scherer S, Wiskemann J, Steindorf K. Return to work after breast cancer: The role of treatment-related side effects and potential impact on quality of life. Eur J Cancer Care (Engl) 2019;28(4):e13051.

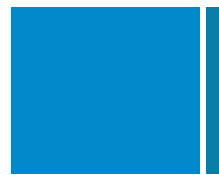

Corresponding author

Leonessa Boing.

Pascoal Simone Street, 358

Coqueiros. Florianopolis, SC - Brazil. Zip postal: 88080-350

Email: leonessaboing@gmail.com 